\title{
Audiological Outcome in Myringoplasties with an Intact Ossicular Chain: Is there a Difference between Chronic Otitis with or without Cholesteatoma?
}

\author{
Eduardo de Barros Sarolli ${ }^{1}$ Christoph Schlegel-Wagner ${ }^{2}$ Thomas Edwin Linder ${ }^{2}$ C) \\ ${ }^{1}$ Department of Otorhinolaryngology, Faculdade Assis Gurgacz, \\ Cascavel, Paraná, Brazil \\ 2 Department of Otorhinolaryngology - Head and Neck Surgery, \\ Luzerner Kantonsspital, Luzern, Switzerland \\ Address for correspondence Thomas Edwin Linder, PhD, Department \\ of Otorhinolaryngology, Luzerner Kantonsspital, Spitalstrasse, \\ Luzern 600, Switzerland (e-mail: Thomas.Linder@luks.ch).
}

Int Arch Otorhinolaryngol 2021;25(2):e224-e228.

\begin{abstract}
Keywords

- chronic otitis media

- cholesteatoma

- hearing outcome

- air-bone gap

- tympanoplasty
\end{abstract}

Introduction Chronic otitis media (COM) with a central perforation or a concomitant cholesteatoma are both inflammatory lesions, however, with different etiologies. Both entities may present with an intact chain, and the final reconstruction is quite similar. Does it also apply for the hearing outcome?

Objectives In a retrospective analysis, we investigated the preoperative hearing and the final hearing outcome of two groups of patients: those with COM and those with cholesteatoma, and compared various factors.

Methods Patients operated between 2010 and 2019 were entered prospectively into a research database, and the integrity of the ossicular chain, the extent of the cholesteatoma, and the findings on computed tomography (CT) scans were retrospectively analyzed and correlated to the final hearing outcome.

Results Out of 210 tympanoplasties for COM, $162(80 \%)$ presented with an intact chain, and 85 (40\%) ears could be analyzed. Out of 283 cholesteatoma surgeries, 53 (19\%) ears presented with an intact chain. The preoperative air-bone gap (ABG) was worse in the COM group, but the postoperative $A B G$ over the frequencies of $0.5 \mathrm{kHz}$ and $4 \mathrm{kHz}$ was the same $(10 \mathrm{~dB}$ to $12 \mathrm{~dB}$ ) in both groups, and remained within $20 \mathrm{~dB}$ in $90 \%$ ( 40 and 78 patients, respectively). The extension of the disease was rather limited in the cholesteatoma group (stages Ch1a and 1b), and better pneumatization and ventilation were beneficial for a good result. Postoperatively, the frequency of $4 \mathrm{kHz}$ had the largest $\mathrm{ABC}(14 \mathrm{~dB}$ and $18 \mathrm{~dB})$.

Conclusion Overall, $80 \%$ of the patients with COM and less than $20 \%$ of those with cholesteatoma had an intact and mobile chain at surgery. Using equivalent surgical techniques for the tympanoplasty, the final outcome was almost the same for both groups, with a mean $\mathrm{ABG}$ of $10 \mathrm{~dB}$ to $12 \mathrm{~dB}$. received

December 28, 2019

accepted

March 12, 2020

published online

June 23, 2020
DOI https://doi.org/ 10.1055/s-0040-1710306 ISSN 1809-9777.

\footnotetext{
(c) 2020. Fundação Otorrinolaringologia. All rights reserved.

This is an open access article published by Thieme under the terms of the Creative Commons Attribution-NonDerivative-NonCommercial-License, permitting copying and reproduction so long as the original work is given appropriate credit. Contents may not be used for commercial purposes, or adapted, remixed, transformed or built upon. (https://creativecommons.org/ licenses/by-nc-nd/4.0/) Thieme Revinter Publicações Ltda., Rua do Matoso 170, Rio de Janeiro, RJ, CEP 20270-135, Brazil
} 


\section{Introduction}

Chronic otitis media (COM) is defined as an inflammation of the middle ear and mastoid mucosa with more than 3 months of duration. In case of an intact eardrum, the most frequent entity is otitis media with effusion (OME), whereas a chronic inflammation with a central perforation is termed as chronic suppurative otitis media (CSOM) or otitis media chronica simplex (OMCS). Intermittent or persistent otorrhea may be a leading symptom besides a moderate hearing loss. The prevalence of an intact ossicular chain in cases of COM has been reported in the literature to range from $72 \%$ to $90 \%$.,2 Size matters regarding the perforation and its impact on the preoperative air-bone gap (ABG). An almost linear correlation between the size of the perforation and the $A B G$ in cases of an intact and mobile chain was documented in a recent publication. ${ }^{3}$ Chronic otitis media with cholesteatoma (Chole) is defined as skin and retention of keratin in the middle ear and/or temporal bone with surrounding inflammatory reaction and progressive bone resorption. Intermittent or persistent foul smelling otorrhea combined with progressive hearing impairment are the leading symptoms. Due to the aggressiveness of the disease, the prevalence of an intact ossicular chain is markedly reduced, and it has been reported to range between $5.5 \%$ and $30 \% .{ }^{4-9}$ Most often, the preoperative $A B G$ is quite variable and cannot be predicted, since the Chole mass itself may transmit sound to the stapes footplate even in severely impaired ossicles. We have recently presented our Chole staging system, coding the extent of the disease, the integrity of the ossicular chain, the type of complications (by the Chole) and a rating of mastoid pneumatization and ventilation. ${ }^{10}$

In both disease entities (COM and Chole) with an intact ossicular chain, the final steps of surgery are equal and consist in the preservation of the ossicles and reconstruction of the tympanic membrane. Our study addressed three research questions: 1) Is the final outcome "normal" hearing with closure of the ABG? 2) Do patients with Chole present a worse result than patients with "simple" perforations? 3) What is the impact of the mastoid pneumatization/ventilation on the hearing outcome in cholesteatomatous patients?

\section{Materials and Methods}

All patients operated at our tertiary referral center are entered prospectively into an otology database (InnoForce, Ruggell, Liechtenstein). We retrospectively analyzed the data of patients operated by two senior surgeons using the same surgical technique in the period from 2010 to 2019. We only selected patients with the diagnosis of COM or Chole and an intraoperatively intact and mobile ossicular chain. Patients with insufficient follow-up (shorter than 3 months) or residual/recurrent disease were excluded. The pre- and latest postoperative pure tone audiograms were analyzed for the individual frequencies as well as the average between $0.5 \mathrm{kHz}$ and $4 \mathrm{kHz}$. The degree of pneumatization and ventilation and the location of the disease in Chole patients was coded by the surgeon by applying the criteria of the ChOLE classification (https://chole.surgery) and evaluating the preoperative computed tomography (CT) scans. Most patients with COM did not have a preoperative CT scan or tympanometric volume measurement, and therefore could not be analyzed regarding their "Eustachian tube" function. The ENT Statistics software Innoforce-cerative solutions (Industriestrasse 56, 9491 Ruggeli, Liechtenstein) was used for the statistical analysis. The MannWhitney $U$ test was used to compare the preoperative, postoperative and the improvement of the mean ABG and isolated frequencies among the different groups. The ranges of the mean ABGs and frequencies between $0.5 \mathrm{kHz}$ and $4 \mathrm{kHz}(0.5 \mathrm{kHz}, 1 \mathrm{kHz}, 2 \mathrm{kHz}, 3 \mathrm{kHz}$, and $4 \mathrm{kHz})$ were all considered for comparison.

The present study was approved by the local Ethics Committee under protocol number 2019-00914.

\section{Results}

The initial COM group consisted of 210 surgeries in 182 patients who underwent primary tympanoplasty with temporalis fascia or tragal cartilage. Out of this group, 162 ears had an intact ossicular chain (80\%) and 77 were excluded because they did not meet the inclusion criteria or due to insufficient follow-up. Finally, the group with COM with intact ossicular chain involved 85 ears (43 left and 42 right ears, 50\% each). Overall, 38 (45\%) patients were male, and 47 (55\%) were female. The average age was 34.3 years at the time of the surgery (range 6.4 to 84.3 years).

In the second group with Chole, 279 patients (283 operated ears) with primary closed cavity tympanomastoid surgery and tympanoplasty using temporalis fascia or cartilage were initially enrolled. All of them had been classified using the ChOLE staging system. A subgroup analysis (-Table 1 ) of these patients examined the impact of the location (Ch1a to $\mathrm{Ch} 4 \mathrm{~b})$, the status of the ossicular chain (O0 to $\mathrm{O} 4 \mathrm{~b}$ ) and the impairment of pneumatization and ventilation (E0 to Ex).

Only 53 operated ears presented with an intact ossicular chain, classified as 00 , and 9 patients were excluded due to insufficient follow-up. The final Chole group consisted of 44 ears (21 left and 23 right ears) of 22 male (50\%) and 22 (50\%) female patients. The average age at the time of surgery was 38.3 years (range 4.1 to 81.7 years) -Tables 1 \& 2 . For consistency a minor change could be made: The extension of

Table 1 Overall classification of all cholesteatomas

\begin{tabular}{|l|l|l|l|l|l|}
\hline Ch stage & N & $\%$ & E stage & $\mathbf{n}$ & $\%$ \\
\hline Ch1a & 112 & $39 \%$ & E0 & 75 & $26 \%$ \\
\hline Ch1b & 48 & $17 \%$ & E1 & 72 & $26 \%$ \\
\hline Ch2a & 28 & $10 \%$ & E2 & 126 & $44 \%$ \\
\hline Ch2b & 17 & $6 \%$ & Ex & 10 & $4 \%$ \\
\hline Ch3 & 34 & $12 \%$ & & & \\
\cline { 1 - 3 } Ch4a & 42 & $15 \%$ & & & \\
\cline { 1 - 2 } Ch4b & 2 & $1 \%$ & & & \\
\hline Total & 283 & $100 \%$ & Total & 283 & $100 \%$ \\
\hline
\end{tabular}


Table 2 Classification of operated ears with cholesteatoma and an intact ossicular chain

\begin{tabular}{|l|l|l|l|l|l|}
\hline Ch stage & $\mathbf{N}$ & $\%$ & E stage & $\mathbf{n}$ & $\%$ \\
\hline Ch1a & 30 & $68 \%$ & E0 & 24 & $55 \%$ \\
\hline Ch1b & 10 & $23 \%$ & E1 & 7 & $16 \%$ \\
\hline Ch2a & 1 & $2 \%$ & E2 & 9 & $20 \%$ \\
\hline Ch2b & 2 & $5 \%$ & Ex & 4 & $9 \%$ \\
\hline Ch3 & 1 & $2 \%$ & & & \\
\hline Total & 44 & $100 \%$ & Total & 44 & $100 \%$ \\
\hline
\end{tabular}

Table 3 Mean pre- and postoperative hearing outcome

\begin{tabular}{|l|l|l|l|}
\hline & $\begin{array}{l}\text { Chole } \\
\text { group } \\
(\boldsymbol{n}=\mathbf{4 4})\end{array}$ & $\begin{array}{l}\text { COM } \\
\text { group } \\
(\boldsymbol{n}=\mathbf{8 5})\end{array}$ & $\boldsymbol{p}$ Value \\
\hline $\begin{array}{l}\text { Preoperative } \\
\text { ABG (dB) }\end{array}$ & 11.8 & 20 & $\boldsymbol{p}=\mathbf{0 . 0 0 0 0}$ \\
\hline $\begin{array}{l}\text { Postoperative } \\
\text { ABG (dB) }\end{array}$ & 11.2 & 10.8 & $p=0.8935$ \\
\hline $\begin{array}{l}\text { Improvement } \\
\text { of ABG (dB) }\end{array}$ & 0.7 & 9.2 & $\boldsymbol{p}=\mathbf{0 . 0 0 0 1}$ \\
\hline $\begin{array}{l}\text { Preoperative } \\
\text { AC (dB) }\end{array}$ & 24.8 & 33.1 & $\boldsymbol{p}=\mathbf{0 . 0 0 0 7}$ \\
\hline $\begin{array}{l}\text { Postoperative } \\
\text { AC (dB) }\end{array}$ & 25.4 & 25.7 & $p=0.8597$ \\
\hline $\begin{array}{l}\text { Improvement } \\
\text { of AC (dB) }\end{array}$ & -0.5 & 7.4 & $\boldsymbol{p}=\mathbf{0 . 0 0 0 4}$ \\
\hline
\end{tabular}

Abbreviations: $A B G$, air-bone gap; $A C$, air conduction; $\mathrm{dB}$, decibels.

the disease among the cholesteatomatous patients in this group was limited (Ch1 in $90 \%$, versus $57 \%$ out of the overall group), and they had better pneumatization and ventilation (E0 in $55 \%$ versus $26 \%$ ) than the patients with ossicular destruction (- Tables $\mathbf{1}$ and $\mathbf{2}$ ).

-Table 3 summarizes the differences between the two groups for the pre- and postoperative audiograms. The mean preoperative $A B G$ of $12 \mathrm{~dB}$ in the Chole group was significantly better than the almost $20 \mathrm{~dB}$ of the COM group. The final $\mathrm{ABG}$ of the two groups was $11.2 \mathrm{~dB}$ and $10.8 \mathrm{~dB}$ respectively, and did not differ significantly anymore. The final air
Table 5 Postoperative air-bone gap for both groups

\begin{tabular}{|l|l|l|}
\hline $\begin{array}{l}\text { Postoperative } \\
\text { ABG }(\mathrm{dB})\end{array}$ & $\begin{array}{l}\text { Chole group } \\
(\boldsymbol{n}=\mathbf{4 4 )}\end{array}$ & $\begin{array}{l}\text { COM group } \\
(\boldsymbol{n}=\mathbf{8 5})\end{array}$ \\
\hline $0-10 \mathrm{~dB}$ & $19(43 \% ;<20 \mathrm{~dB})$ & $45(53 \% ;<20 \mathrm{~dB})$ \\
\hline$<20 \mathrm{~dB}$ & $40(93 \%)$ & $78(92 \%)$ \\
\hline $20-30 \mathrm{~dB}$ & $2(5 \%)$ & $7(8 \%)$ \\
\hline$>30 \mathrm{~dB}$ & $1(2 \%)$ & $0(0 \%)$ \\
\hline
\end{tabular}

Abbreviations: $A B G$, air-bone gap; Chole, cholesteatoma; COM, chronic otitis media; $\mathrm{dB}$, decibel.

Table 6 Degree of pneumatization and hearing outcome in cholesteatoma patients

\begin{tabular}{|l|l|l|l|l|}
\hline & $\begin{array}{l}\text { E0 } \\
(\boldsymbol{n}=\mathbf{2 4 )})\end{array}$ & $\begin{array}{l}\text { E1 } \\
(\boldsymbol{n}=\mathbf{7})\end{array}$ & $\begin{array}{l}\text { E2 } \\
(\boldsymbol{n}=\mathbf{9})\end{array}$ & $\begin{array}{l}\text { Ex } \\
(\boldsymbol{n}=\mathbf{4})\end{array}$ \\
\hline $\begin{array}{l}\text { Preoperative } \\
\text { ABG (dB) }\end{array}$ & 10.7 & 12.5 & 11.1 & 15.4 \\
\hline $\begin{array}{l}\text { Postoperative } \\
\text { ABG (dB) }\end{array}$ & 9.4 & 14.7 & 9.4 & 16.9 \\
\hline Improvement (dB) & 1.3 & -2.2 & 1.7 & -1.5 \\
\hline
\end{tabular}

Abbreviations: $A B G$, air-bone gap; $d B$, decibel.

conduction for the mean frequencies between $0.5 \mathrm{kHz}$ and $4 \mathrm{kHz}$ was $25 \mathrm{~dB}$ for both entities. Therefore, the overall hearing improvement was higher in COM patients. Analyzing individual frequencies ( - Table 4 ), the Chole group had a better preoperative $A B G$ in each one in comparison with the COM group $(p<0.05)$. Postoperatively, they no longer differed from each other. The lowest ABG was consistently found at $2 \mathrm{kHz}$, whereas the predominant $A B G$ was at $0.5 \mathrm{kHz}$ and $4 \mathrm{kHz}$. A postoperative $\mathrm{ABG}<20 \mathrm{~dB}$ is considered a successful outcome in most studies. In the Chole group, 40 ears (93\%) reached this goal, and $19(43 \%)$ of those had an $\mathrm{ABG}<10 \mathrm{~dB}$. In total, $2(5 \%)$ patients remained with a postoperative $A B G$ between $20 \mathrm{~dB}$ and $30 \mathrm{~dB}$, and 1 patient presented with a poor result $(A B G>30 \mathrm{~dB})$. In the $C O M$ group 78 ears (92\%) remained within $<20 \mathrm{~dB}$, and $45(53 \%)$ had results $<10 \mathrm{~dB}$. A total of $7(8 \%)$ patients had ABGs between $20 \mathrm{~dB}$ and $30 \mathrm{~dB}$, and none of the patients in this group had an $A B G>30 \mathrm{~dB}$. The results are presented in the - Table 5.

As part of the study, we evaluated the hearing outcome in the Chole group considering the ChOLE classification. The

Table 4 Pre- and postoperative air-bone gap single frequencies for both groups

\begin{tabular}{|l|l|l|l|l|l|l|}
\hline Frequencies $(\mathrm{kHz})$ & Chole group $(\mathrm{dB})$ & COM group $(\mathrm{dB})$ & $\boldsymbol{p}$ Value & Chole group (dB) & COM group (dB) & $\boldsymbol{p}$ Value \\
\hline $\mathbf{0 . 5}$ & 13.1 & 21.1 & $\boldsymbol{p}=\mathbf{0 . 0 0 1 5}$ & 12.6 & 10.6 & NS \\
\hline $\mathbf{1}$ & 13.5 & 20.4 & $\boldsymbol{p}=\mathbf{0 . 0 0 1 6}$ & 11.9 & 10.3 & NS \\
\hline $\mathbf{2}$ & 7.1 & 16.6 & $\boldsymbol{p}=\mathbf{0 . 0 0 0 0}$ & 4.4 & 5.0 & NS \\
\hline $\mathbf{3}$ & 9.6 & 19.7 & $\boldsymbol{p}=\mathbf{0 . 0 0 0 0}$ & 9.8 & 9.4 & NS \\
\hline $\mathbf{4}$ & $\mathbf{p}$ & $\mathbf{p}=\mathbf{0 . 0 0 2 1}$ & 13.9 & 17.6 & NS \\
\hline & $\mathbf{2}$ & \multicolumn{2}{l}{ Postoperative air-bone gap } \\
\hline
\end{tabular}

Abbreviations: Chole, cholesteatoma; COM, chronic otitis media; dB, decibel; kHz, kilohertz; NS, not significant. 
individual stages are presented in - Table 2 . The size and location of the Chole had no impact on the final hearing outcome $(p>0.05)$, and there was no patient with a large extension of Ch4a or Ch4b. On the other hand, the group with moderate to good pneumatization and ventilation (E0) achieved a significantly better $(p=0.0413)$ postoperative ABG of $9.4 \mathrm{~dB}$ (-Table 6) compared with the patients with reduced ventilation (E1) and a mean $A B G$ of $14.7 \mathrm{~dB}$. The hearing outcome of the patients with sclerotic mastoids (E2) was almost to the same as that of the E0 subgroup and did not show a significant difference to the E1 subgroup, due to the limited number of patients in both groups.

\section{Discussion}

There are various forms of COM, and all of them - to a different degree - impair sound conduction and, therefore, lead to a conductive hearing loss. Patients with COM with and without suppurative episodes (CSOM) contact their physician to get a dry and stable ear with an intact eardrum, and ask for improvement of their hearing hoping for "normal hearing." In our series, $80 \%$ of all COM patients present at surgery with an intact and mobile ossicular chain. In a previous publication, ${ }^{3}$ we confirmed that the size (and not the location) of the tympanic-membrane perforation had a direct and almost linear impact on the preoperative hearing impairment in these patients. The least severe effect was found at the middle-ear resonance frequency of $2 \mathrm{kHz}$, and the most pronounced impact, at the low $(0.5 \mathrm{kHz})$ and high $(4 \mathrm{kHz})$ frequencies. Even in cases of subtotal perforations, the preoperative $A B G$ did not exceed $35 \mathrm{~dB}$. On the other hand, patients with middle-ear Choles contact their physician to completely remove the disease, get rid of the foul smelling otorrhea, and hope for some hearing improvement. Choles are much more aggressive. Considering the ChOLE classification, ${ }^{10}$ the size and extension of the disease is generally correlated with a higher surrounding bone reabsorption and ossicular erosion. Indeed, in our series, only $20 \%$ of all patients presented with an intact ossicular chain. In comparison to the other cholesteatoma patients, their extent of the disease was rather limited (stage- 1 Chole in $80 \%$ or 35 out of 44 cases), and they had better pneumatization and ventilation on the preoperative CT scans. Contrary to the COM patients, the extent of the Chole did not have a direct impact on the preoperative $A B G$. The mean preoperative $A B G$ of $12 \mathrm{~dB}$ in the Chole group was significantly better than the almost $20 \mathrm{~dB}$ of the COM group, and this was also true for the individual frequencies. In summary, the chance to encounter an intact and mobile chain in cases of COM is of $80 \%$, and it drops to less than $20 \%$ in patients with limited cholesteatomatous ear disease, whereas the preoperative hearing may be better in the Chole patients and is unpredictable.

At the end of the surgery, once the eardrum has been reconstructed, surgeons and patients hope for optimal hearing improvement, and may even expect "normal" hearing in cases of an intact and mobile ossicular chain and closed cavity setting. One might expect that patients with Chole present with a worse outcome due to the severity of the inflammatory disease. However, our results reveal some interesting findings. First, there was no difference between the groups regarding the final postoperative ABG. More than $90 \%$ had an ABG $(0.5-4 \mathrm{kHz}$ ) lower than $20 \mathrm{~dB}$ (and $19(43 \%)$ in the Chole and $45(53 \%)$ in the COM group within $10 \mathrm{~dB}$ ) and only 3 patients in the Chole group had an ABG higher than $20 \mathrm{~dB}$. Reviewing the charts of these 3 patients, they had minor erosion of the incus (but still with an intact incudostapedial joint at the first surgery) and 1 patient underwent an ossiculoplasty 2 years later, with hearing improvement. In the COM group, 7 patients (8\%) ended with an ABG $>20 \mathrm{~dB}$. Specifically analyzing these cases, we did not find a consistent factor, but the presence of glue, a more severely inflamed middle-ear mucosa or a postoperative eardrum retraction and atelectasis as reasonable explanations. Secondly, the relative hearing improvement was better among the COM patients, but this is due to the fact that the preoperative hearing was worse and the final outcome, the same. Thirdly, we looked at the impact of pneumatization and ventilation, which could be encoded for the Chole group using the ChOLE classification. Unfortunately, we did not perform routine CT scans in the COM patients, and did not record routinely the preoperative volume on tympanometry. Patients with reasonably good ventilation (E0 on the ChOLE score) had a higher chance of having an intact chain and a better hearing outcome, suggesting a positive effect of the function of the Eustachian tube. However, a final statement cannot be made yet.

Table 7 Literature overview

\begin{tabular}{|c|c|c|c|c|c|c|c|c|c|}
\hline Thresholds (kHz) & Author & Year & Disease & $\mathrm{n}$ & $\begin{array}{l}\text { Preop } \\
\text { ABG }\end{array}$ & $\begin{array}{l}\text { Postop } \\
\text { ABG }\end{array}$ & $\begin{array}{l}\text { Preop } \\
\text { AC }\end{array}$ & $\begin{array}{l}\text { Postop } \\
\text { AC }\end{array}$ & Remarks \\
\hline $0.5-4$ & Our study & 2020 & COM & 85 & 20 & 10.8 & 33.1 & 25.7 & \\
\hline $0.5-4$ & Our study & 2020 & Chole & 44 & 11.8 & 11.2 & 24.8 & 25.4 & \\
\hline $0.5-3$ & Horvath et al ${ }^{1}$ & 2019 & COM & 147 & 22.1 & 17.2 & & & \\
\hline $0.5-3$ & Ohki et al ${ }^{11}$ & 2019 & COM & 122 & $\begin{array}{l}19.7 \\
20.3\end{array}$ & $\begin{array}{l}10.1 \\
13.1\end{array}$ & $\begin{array}{l}43.4 \\
42.3\end{array}$ & $\begin{array}{l}32.7 \\
33.9\end{array}$ & $\begin{array}{l}\text { Endoscopic } \\
\text { Microscopic }\end{array}$ \\
\hline $0.5-4$ & Pontillo et $\mathrm{al}^{4}$ & 2018 & Chole & 65 & $\begin{array}{l}11,7 \\
17,4\end{array}$ & $\begin{array}{l}7.7 \\
12.9\end{array}$ & $\begin{array}{l}27.7 \\
41.2\end{array}$ & $\begin{array}{l}23.1 \\
35.1\end{array}$ & $\begin{array}{l}\text { Canal wall up } \\
\text { Canal wall down }\end{array}$ \\
\hline $0.5-3$ & Hamilton $^{12}$ & 2010 & Chole & 80 & & 11.4 & & & Use of KTP laser \\
\hline
\end{tabular}

Abbreviations: ABG, air-bone gap; AC, air conduction; Chole, cholesteatoma; COM, chronic otitis media; dB, decibel; kHz, kilohertz; KTP, potassium titanyl phosphate; Postop, postoperative; Preop, preoperative. 
Interestingly, not many previous publications have addressed this research question. A comparison is also limited, since some journals require the presentation of the hearing data for the frequencies between $0.5 \mathrm{kHz}$ and $3 \mathrm{kHz}$, and do not ask for data regarding $4 \mathrm{kHz}$. It is known that the high frequencies (including $4 \mathrm{kHz}$ ) are more important for speech understanding and the overall benefit to the patients. Our data reveal that the closure of the ABG was rather limited at $4 \mathrm{kHz}$. Therefore, excluding this important frequency would improve the surgeon's success rates, but does not honestly summarize the benefit for the patient. So far we do not routinely ask for postoperative speech audiograms, and, therefore, did not have enough data for comparison. - Table 7 summarizes the results of previous studies in the literature. They are quite similar to our findings, with reported postoperative ABGs of $10 \mathrm{~dB}$ to $17 \mathrm{~dB}$ for COM and $10 \mathrm{~dB}$ to $13 \mathrm{~dB}$ in Chole patients. As more and more surgeons switch to an endoscopic approach, it will be very interesting to see the results, since during the endoscopy, most ear surgeons completely detach the remaining eardrum from the malleus handle to access the anterior extensions of the middle-ear disease. The impact of lifting and reinstating the drum from the umbo and malleus handle has not yet been properly addressed. One study by Ohki et $\mathrm{al}^{11}$ ended with a favorable postoperative $A B G$ for the endoscopic as well as microscopic groups (Tabel 7), with comparable hearing outcomes and no inner ear damage. The use of lasers to detach choles from an intact chain has been advocated to preserve the integrity of the chain, and it revealed better and more reliable hearing outcomes in comparison to the more conventional approach of dismantling the chain and reconstructing the gap. ${ }^{12}$

\section{Conclusion}

Statistically, $80 \%$ of the patients with COM will have an intact and mobile chain at surgery, whereas less than $20 \%$ retain their intact chain in cases of Chole. Preoperatively, patients with eardrum perforations (COM) present with worse hearing thresholds than patients with Chole and an intact ossicular chain. Postoperatively, their performance is almost the same, with a mean $\mathrm{ABG}$ of $10 \mathrm{~dB}$ to $12 \mathrm{~dB}$, which enables a higher hearing gain for COM patients. Roughly, $50 \%$ will end up with an $A B G$ lower than $10 \mathrm{~dB}$, and $90 \%$, within $20 \mathrm{~dB}$. In chole patients, the extent of the disease is small, and it seems that better pneumatization and ventilation leads to improved outcomes. It remains difficult to close the ABG at $4 \mathrm{kHz}$, a frequency that should not be neglected when presenting outcome data.

\section{Conflict of Interests}

The authors have no conflict of interests to declare.

\section{References}

1 Horvath T, Lukacs D, Horvath B, Ferenci T, Liktor B. Does the type of ossicular chain lesion affect outcomes in chronic suppurative otitis media without cholesteatoma? J Int Adv Otol 2019;15(01):28-33

2 Albera R, Dagna F, Filippini C, Albera A, Canale A. Ossicular chain lesions in tympanic perforations and chronic otitis media without cholesteatoma. J Int Adv Otol 2015;11(02):143-146

3 Lerut B, Pfammatter A, Moons J, Linder T. Functional correlations of tympanic membrane perforation size. Otol Neurotol 2012;33 (03):379-386

4 Pontillo V, Barbara F, DE Robertis V, Quaranta N. Treatment of cholesteatoma with intact ossicular chain: anatomic and functional results. Acta Otorhinolaryngol Ital 2018;38(01):61-66

5 Lailach S, Zahnert T, Lasurashvili N, Kemper M, Beleites T, Neudert M. Hearing outcome after sequential cholesteatoma surgery. Eur Arch Otorhinolaryngol 2016;273(08):2035-2046

6 Smouha EE, Javidfar J. Cholesteatoma in the normal hearing ear. Laryngoscope 2007;117(05):854-858

7 Martins O, Victor J, Selesnick S. The relationship between individual ossicular status and conductive hearing loss in cholesteatoma. Otol Neurotol 2012;33(03):387-392

8 Mohammadi G, Naderpour M, Mousaviagdas M. Ossicular erosion in patients requiring surgery for cholesteatoma. Iran J Otorhinolaryngol 2012;24(68):125-128

9 Albera R, Canale A, Piumetto E, Lacilla M, Dagna F. Ossicular chain lesions in cholesteatoma. Acta Otorhinolaryngol Ital 2012;32(05): 309-313

10 Linder TE, Shah S, Martha AS, Röösli C, Emmett SD. Introducing the "ChOLE" classification and its comparison to the EAONO/JOS Consensus Classification for cholesteatoma staging. Otol Neurotol 2019;40(01):63-72

11 Ohki M, Kikuchi S, Tanaka S. Endoscopic Type 1 tympanoplasty in chronic otitis media: comparative study with a postauricular microscopic approach. Otolaryngol Head Neck Surg 2019;161(02):315-323

12 Hamilton JW. Systematic preservation of the ossicular chain in cholesteatoma surgery using a fiber-guided laser. Otol Neurotol 2010;31(07):1104-1108 